\title{
ALOCUÇÃO PROFERIDA PELO PRESIDENTE DO CENTRO REGIONAL DAS BEIRAS DA UNIVERSIDADE CATÓLICA PORTUGUESA
}

Eça, numa das suas cartas a Oliveira Martins, percorre um dos seus cenários do Portugal Queirosiano: "Filho de Aveiro, educado na Costa Nova, quase peixe da ria, eu não preciso que mandem ao meu encontro caleches e barcaças. Eu sei ir por meu próprio pé ao velho e conhecido "palheiro do José Estevão»".

Celso Tavares da Silva, oriundo de Cedrim, aldeia bem próxima de Sever do Vouga, não poderia dizer o mesmo. Nascido e criado em terras percorridas pelo Vouga, há bem pouco tempo me descrevia, com saudade, as suas viagens em barcaça com a mãe e outros familiares e amigos, desde Pessegueiro do Vouga até esse cenário queirosiano onde iria veranear ou, talvez com mais propriedade, outonar, pois já era depois das vindimas, em praias da ria e do litoral aveirense. As mulheres e os miúdos iam na barcaça, duas ou três famílias; os homens viajavam de cavalo ou de comboio, quando o passou a haver, pois sempre encurtavam dois dias da jornada, no rio e na ria.

Mas os seus estudos preparatórios e de teologia, que concluiu com distinção no seminário de Viseu, trouxeram-no a estas terras altas da Beira. Terras de serrania e pinhais que descem dos céus aos rios. Das alvas ermidas e do granito. Dos castros e dos solares nobres. Da cozinha de saber conventual. Pois por estas serras e planaltos beirões se veio a fixar o Padre Celso, quando optou por continuar na Diocese de Viseu, aquando da restauração da Diocese de Aveiro, a que o poderiam ligar laços da sua terra e dos seus tempos de criança.

Com certeza encontrou nestas terras da Beira a humildade sincera que, celebrada pelo Evangelho, havia nascido em si fruto das raízes mais recônditas do seu ser moral e do exemplo de seus pais e de quantos, na sua casa e na sua terra, contribuíram para o criar e formar. Terá calado fundo no seu coração aquele ambiente que Silva Gaio descreve:

"Da torre da próxima igreja descerá o toque da avé-maria, como benção da tarde que vem de cima; e enquanto vão caminhando silenciosos e recolhidos em breve oração, só ouvireis as campainhas dos gados que se recolhem ao redil. Em 
tudo vereis a crença e a força, o trabalho e a paz, e esta sã virilidade dos povos lavradores, que é o eterno louvor da Natureza".

Começou o Padre Celso por paroquiar Santiago de Besteiros, aqui bem próximo no vale da Serra do Caramulo virado a Tondela, em 1939, quando se caminhava decididamente para a II Grande Guerra. Homem de fé e de acção, com profunda tolerância cristã, inicia o seu pastoreio de almas, com afabilidade e compreensão, sempre pronto a ouvir e aconselhar. Por estas terras se lhe terá avivado o interesse pela arqueologia, ao ter informações sobre os vestígios castrejos que apareciam pela serra. Quiçá interesse que já lhe vinha dos passeios de juventude pelos campos de Cedrim, pois também por lá se encontram vestígios arqueológicos.

Quem folhear o $1 .^{\circ}$ volume da História de Portugal, dirigida por José Mattoso, sobre o nosso passado proto-histórico no período do Bronze Final, encontrará algumas fotografias de exemplares arqueológicos da donominada "Colecção da UCP, Centro de Viseu". Não é o número que aqui é determinante, numa valiosa colecção de artefactos de cobre e ferro, de exemplares cerâmicos, de fíbulas, etc., a que a UCP, através da sua Faculdade de Letras, virá dar expressão de maior relevo, em Viseu, com a criação de um pequeno, mas rico museu de arqueologia. Mas é o valor arqueológico que patenteiam e o que representam na caracterização do "Grupo da Beira Alta". E passo a citar da obra em referência: "Muito menos conhecido que as realidades culturais do Nordeste, mas parecendo possuir uma individualidade própria, é o grupo de povoados do Bronze Final da Beira Alta. Estende-se desde a vertente norte-ocidental da Serra da Estrela e vem até à margem do Vouga, no povoado da Senhora da Guia, em Baiões (S. Pedro do Sul), com outros nos povoados de Santa Luzia e Senhora do Castro."

Nomeadamente, a Senhora da Guia apresenta uma grande exuberância de artefactos metálicos relevando a riqueza do povoado, com imensos utensílios abandonados no local por qualquer circunstância de abandono ou desertificação inesperada. Pois bem, muitos destes estudos, descobertas e materiais recolhidos, devem-se às investigações proficientes, criteriosas e dedicadas do arqueólogo Celso Tavares da Silva. Inteligente e culto, cedo revelou propensão para os estudos arqueológicos. Publicou diversos trabalhos na Revista Beira Alta e em Congressos de Arqueologia, alguns em co-autoria, com citações em livros e em artigos de eminentes arqueólogos nacionais e estrangeiros. Como agora se diz, "indicadores do impacto da obra" e do reconhecimento pelos seus pares que o levaram a ser membro de Associações de Arqueólogos, de Arqueologia e de Museologia no país e no estrangeiro, e a figurar no "Who's who in Rock Art".

Na sua obra destacam-se os importantíssimos estudos sobre o Castro de Baiões. Situa-se na freguesia do mesmo nome, no chamado Monte da Senhora da Guia e faz parte de um conjunto de elevações sobranceiras ao Vouga, o seu 
Vouga, como primeiros contrafortes da serra da Gralheira. Já no séc. XVIII se encontraram referências a achados de pedaços de "ouro lavrado" no monte da Senhora da Guia. Mais vestígios haviam sido encontrados em 1947, por ocasião da abertura de uma rua e em 1971, por ocasião de outras obras; entre vária cerâmica fora descoberto um conjunto de peças de bronze. Em 1973 o arqueólogo Tavares da Silva dirige as primeiras escavações, cujos resultados logo comunica em congresso. Dado o interesse da descoberta, os estudos prosseguem com a colaboração de outros especialistas portugueses, alemães e holandeses. De um dos trabalhos do Padre Celso passo a citar:

"Antes da datação de Baiões [674 a.C.], a cronologia mais antiga, obtida pelo mesmo processo de $\mathrm{C}-14$, pertencia ao castro de Borneiro, na Corunha, que lhe atribuía o séc. VI a.C.; e era, a partir daqui, que alguns autores marcavam o começo da cultura castreja. Baiões, antecipando-se em mais de um século, não só contesta a opinião firmada, mas ainda põe a interrogação sobre a localização do centro de irradiação desta cultura, possivelmente a partir da Beira Alta, donde se terá expandido para o Norte, atraída pela fertilidade da zona da humidade atlântica e riqueza metalífera".

Tal datação está de acordo com o contexto do material exumado, com excepção da presença de "cerâmica estampada", cuja introdução na cultura castreja, segundo Savory, andaria à volta de 500 a.C.. E citando de novo o nosso homenageado: "A dificuldade dimanava da presença de cerâmica estampada, comummente considerada do Ferro e tipicamente castreja, ao lado de padrões de características arcaizantes, sem que, no desenrolar das escavações, se tivessem constatado estratigrafias comprovativas de uma ocupação posterior do castro". Tavares da Silva, agora com a colaboração de dois arqueólogos alemães, retoma as sondagens no castro de Baiões, que não alteraram as suas anteriores conclusões. Houve pois que rever a datação da "cerâmica estampada", visto que, em Baiões, ela se insere rigorosamente numa datação da primeira metade do séc. VII a.C.. E continuo a citação do mesmo trabalho. "É pois, sem dúvida alguma, para o coração das Beiras, que as atenções dos arqueólogos e antropólogos hão-de convergir para se encontrarem as raízes e o cerne da raça lusitana".

A partir de 1975, o Padre Celso dirige também diversas campanhas de escavações num outro castro vizinho na serra da Arada, o Castro de Cárcoda, que é outro expoente da mesma cultura, mas que pela sua inacessibilidade resistiu ao invasor romano, perdurando tranquilo e duradoiro até ao séc. III ou IV da nossa era.

Pároco e Arcipreste em Oliveira de Frades, o vamos encontrar em 1954. Já com longa experiência do convívio com as gentes de Lafões a sua integridade, a sua rectidão de carácter, o seu testemunho de cristão e de sacerdote, aliados à sua fineza de trato e dotes oratórios, e a um ardor combativo pelo desenvolvimento das suas gentes e progresso da região, levam-no a uma intensa actividade apostó- 
lica e a um inestimável trabalho de promoção social, com enorme aceitação dos seus paroquianos. Ei-lo a fundar o " Externato Lafonense" de que foi Director, o Jornal de Lafóes e um Movimento de Promoção de Oliveira de Frades: Tudo isto, e muito mais que fica por dizer, promoveram o surto de desenvolvimento que conheceu esta vila beirã.

Atento às suas qualidades humanas, de inteligência, trabalho e dedicação à Igreja, em 1968 o Bispo de Viseu chama-o para o Seminário de Viseu, como Vice-reitor e Professor. Em 1977, por falecimento do então reitor, Con. José Henriques Mouta, toma posse do lugar de Reitor do Seminário de Viseu, cargo que exerceu até 1988. Elevado, em 1973, à dignidade de Cónego Capitular da Sé de Viseu, em 1982 foi agraciado com o título de Monsenhor pela Santa Sé. Justos e oportunos reconhecimentos pelas autoridades da Igreja Católica ao seu zelo e cooperação no seio da Igreja no santificar, no ensinar, no governar.

Todos nós, os que convivemos com Monsenhor Celso, nos habituámos a admirar a sua fina inteligência, a sua cultura, o encanto da sua conversa, a sua generosa disponibilidade e, até, as fraquezas da sua bondade. Mas a quem recorrer, na Diocese de Viseu, quando o seu Bispo e o Reitor da Universidade Católica procuraram lançar uma nova escola em Viseu? Ao Cónego Celso, naturalmente! Uma experiência diversificada em prol da Igreja, pronto e zeloso no servir, trabalhador infatigável, investigador de méritos firmados e reconhecido pelos seus pares, professor de exposição fácil mas profunda; tudo isto aliado a um coração magnânimo e a uma consciência viva dos valores superiores a cultivar no homem.

Por isso nós estamos a homenageá-lo em nome da Universidade Católica Portuguesa, neste Centro de Viseu que muito lhe deve. Dívida que não é só da Universidade, mas também da Igreja de quem a universidade depende e serve. Mas muito melhor que eu, os Ilustres Colegas que me precederam o fizeram, com mais conhecimento e razão. Não obstante, em nome do recém-criado Centro Regional das Beiras, com sede em Viseu, e na qualidade de seu presidente, compete-me agradecer-vos, pertencendo ou não a esta Casa, mormente aos que mais de longe vieram, porque o quisestes honrar e nos quiseste honrar com a vossa prestigiosa presença.

No cancioneiro beirão encontram-se várias quadras à tristeza. Mas permitam-me que recorra a quadras que me tocam em laços familiares. De uma cançoneta de João de Deus, no seu Campo de Flores e dedicada a Sebastião Formosinho:

Na marcha da vida

Que vai a voar

Por esta descida 
De noite e de dia

Me alveja no ar

O fumo que eu via

Subir do meu lar

Carreira da vida

Que vás a voar

Por esta descida

Vai mais devagar;

Que eu vou deste mundo

Talvez, descansar,

E nunca do fundo

Dos mares voltar! ...

Hora de tristeza? Não, meus amigos, não! Tempo de júbilo, porque ele evoca para Monsenhor Celso a libertação do peso de algumas obrigações e responsabilidades que os médicos lhe recomendam que alivie. $\mathrm{E}$ porque para todos nós representa a aceitação de Monsenhor Celso Tavares da Silva da direcção e organização do Museu Arqueológico da Faculdade de Letras, em Viseu, para o qual conta com o valioso espólio disponibilizado por si próprio e por outros distintos professores e investigadores desta Casa e da Região.

Nesta bela expressão beirã: Bem hajam todos pela vossa presença!

Bem haja Monsenhor, pela dedicação e pelo seu exemplo para todos nós os desta Casa!

Sebastião Formosinho Sanches 